\title{
Review Article \\ The Infection Hypothesis Revisited: Oral Infection and Cardiovascular Disease
}

\author{
Lise Lund Håheim ${ }^{1,2}$ \\ ${ }^{1}$ Institute of Oral Biology, Dental Faculty, University of Oslo, PB 1052 Blindern, 0316 Oslo, Norway \\ ${ }^{2}$ Institute of Basic Medical Sciences, Medical Faculty, University of Oslo, PB 1110 Blindern, 0317 Oslo, Norway \\ Correspondence should be addressed to Lise Lund Håheim; a.l.haheim@odont.uio.no
}

Received 29 June 2014; Revised 22 September 2014; Accepted 23 September 2014; Published 21 October 2014

Academic Editor: Jaume Marrugat

Copyright (C) 2014 Lise Lund Håheim. This is an open access article distributed under the Creative Commons Attribution License, which permits unrestricted use, distribution, and reproduction in any medium, provided the original work is properly cited.

\begin{abstract}
Background. The pathophysiology of cardiovascular disease (CVD) includes inflammation in the development of atherosclerosis and thrombosis. Increasing evidence supports oral infections, and in particular the common periodontal disease, to be associated with CVD development. Periodontal infection is present in populations worldwide and in the moderate to mild form in about $35 \%$ of populations according to the World Health Organization. Objective. This review of the literature aims to present cross evidence from medical research disciplines that explore how oral infections can contribute to increase the risk for CVDs and how treatment of oral infections can reduce the risk for CVDs. Design. Review article. Results. Long-term exposure to active nontreated infections of the oral cavity presents an opportunity for bacteria, bacterial products, and viruses to enter the circulation. Toxic bacterial products enter the circulation, affecting atherosclerosis, causing platelet adhesiveness that results in clot formation, and establishing cardiac vegetation. Pathological observations have identified oral bacteria in heart valves, aortic aneurysms, and arterial walls. Clinical intervention studies on periodontal disease reduce the risk level of serological predictors for CVDs. Conclusions. This paper presents evidence across medical research disciplines for oral infections to be considered as one of the risk factors for CVDs.
\end{abstract}

\section{The Magnitude of Two Health Problems: Cardiovascular Diseases and Oral Infections}

Cardiovascular diseases (CVDs) are common, considered to be $80 \%$ preventable and to cause premature deaths. In Europe, they are the major causes of death being responsible for 1.9 million deaths per year and costing the European Union an estimated $€ 196$ bn (data were presented at the Cardiovascular Health Week in Brussels in November 2013). There has been a huge amount of research activity into the aetiology and risk factor prevention for CVDs and the development of the most effective and efficient treatment modalities for different CVD diagnoses such as coronary heart disease (CHD) and stroke. The reduction in mortality from CVDs is noticeable in many western countries as reported by the World Health Organization, due to improvement in treatment and preventive measures $[1,2]$. A decline in hospitalizations for acute myocardial infarction has been reported in the USA [3]. A reduction in both incidence and mortality of acute myocardial infarction and stroke has been observed [4].
Although great improvements have been achieved and there has been a risk reduction in the high-income countries, there is an increasing trend of CVDs in low-income countries. However, CVDs remain a major cause of death worldwide.

Historically, much attention has been given to the cause and development of atherosclerosis as an inflammation of the arterial wall [4-9]. Attention has also been paid to thrombosis caused by platelet adhesion, which has been shown to increase in the presence of infection [10]. A potential infectious aetiology of the inflammatory condition atherosclerosis has been discussed where infection has been seen as an inflammatory stimulus in association with traditional risk factors in the development of atherosclerosis [11].

Oral infections include periodontal infections, dental infections due to caries and, in later years also periimplantitis, oral mucosal and orofacial infections; all are part of the total infection picture, as are upper and lower respiratory tract infections [12]. Advanced periodontal disease is present in $10-15 \%$ of the adult population whereas moderate or mild forms are present in about 35\% [2]. Data from 
the United States from 2009 and 2010 show that $8.7 \%$ suffer from mild periodontal disease (PD), 30.0\% from moderate $\mathrm{PD}$, and $8.5 \%$ from severe PD [13].

Sugar in the diet is an important substrate for bacteria. Bacteria, viruses, and fungi can be included in the biofilm, dental plaque, of the oral cavity. Infectious agents include over 700 bacteria [14]. The most common viruses are herpes simplex virus type 1 (HSV-1), cytomegalovirus, human papilloma virus, and Epstein-Barr virus [15]. Fungal infections are caused mainly by Candida albicans or other Candida species. Oral parasitic infections may also occur.

Oral infections both periodontal and pulpal ones are often long-standing, with a low level of symptoms but with acute exacerbations [16]. The microbiota of pulpitis and periodontitis are comparable [17]. Thus, the oral environment is a major source of infective agents. It has a systemic role in addition to the local protective role against pathological agents [18-20]. There is much evidence about association between diabetes and PD. Research indicates a bidirectional relationship where $\mathrm{PD}$ is more serious in diabetes and having diabetes increases the risk of PD [21, 22]. There are indications of increased tissue destruction and impaired repair in diabetes associated PD but further longitudinal studies are warranted. Likewise more longitudinal follow-up studies based on randomized controlled trials of clinical treatment of PD in persons with diabetes are needed. Adverse pregnancy outcome as preterm birth has been associated with PD [23]. Maternal PD has been found to be modestly, but significantly, associated with preterm birth ( $<37$ weeks gestation), low birth weight $(<2500 \mathrm{~g})$, and with preeclampsia. So far, studies on the effect of PD treatment such as nonsurgical periodontal therapy, scaling, and root-planing do not show results in improving birth outcomes in pregnant women. Thus a causal relationship has not been fully established [24].

The American Heart Association (AHA), in its guidelines published in Stroke [4] on primary prevention for stroke, lists periodontal disease as one of the less well-documented or potentially modifiable risk factors, with a risk estimate for those aged 25-74 years of 2.11 (95\% confidence interval (CI) 1.30-3.42). A systematic literature review in 2007 on the association between periodontitis and CHD reported in the meta-analyses a relative risk in prospective studies of 1.14 (CI 1.07-1.21), an odds ratio of cross-sectional studies of 1.59 (CI $1.33-1.91$ ), and odds ratio of case-control studies of 2.23 (CI 1.59-3.12) [25]. Other common oral infections with systemic inflammation have been associated with CVD [26].

Later publications summarize the more recent development as there are an increasing number of studies now being published on the association between CVDs and oral infection [27-30]. In 2013, a workshop of the joint European Federation of Periodontology (EFP)/American Academy of Periodontology (AAP) on periodontitis and systemic diseases took place and conclusions were drawn about three major issues [30] as follows.

(1) Epidemiological evidence shows that periodontitis increases the risk of CVD.

(2) The impact of periodontitis on atherosclerotic CVD is biologically plausible because circulating oral microbiota directly or indirectly induce inflammation that impacts the pathogenesis of atherosclerosis.

(3) Interaction and biological mechanisms have been shown in animal, in vitro, and clinical studies which support those mechanisms involved in atherosclerosis.

\section{Literature Search Methodology}

The databases PubMed, Cochrane, and NHS Evidence - oral health were search. The searches were limited to English and Scandinavian languages. Accepted study designs were systematic reviews, randomized controlled studies, metaanalyses, review or cohort studies, and animal studies. Cardiovascular outcome terms were cardiovascular disease, atherosclerosis, myocardial ischemia, peripheral vascular disease, and stroke. Oral infection terms were periodontal disease and oral infection. Outcomes in the studies could be informative concerning mortality and/or risk factor changes. In addition, searches were carried out based on authors and studies. Manual searches of the references in papers were performed.

\section{The Infection Hypothesis}

The infection hypothesis was introduced in 1823 by Rayer, who compared the calcification ("ossification morbide") observed in arteries to that observed in inflammatory conditions elsewhere [31]. Others disputed the pathogenic significance of these observations and discussions of the infection hypothesis were abandoned for a long period in the nineteenth century. Osler, often cited as the "first" to postulate the causal role of the infection hypothesis in arteriosclerosis, wrote in 1908 about the existence of "four great factors in the causation of arteriosclerosis - normal wear and tear of life, the acute infections, the intoxications (including smoking, diabetes mellitus, obesity), and those combinations of circumstances that keep blood tension high" $[31,32]$. Osler described fatty streaks in atheroma as well as their high prevalence in children. It was evident that the authors distinguished between other types of aortitis, as seen in conditions such as syphilis.

In the nineteenth century animal experiments were already being carried out which showed that both endothelial injury and experimental infection were necessary to induce atherosclerosis. Later experiments showed that the effect of infection was greater in the presence of a high-cholesterol diet. Further animal experiments have shown that periopathogens inoculated into rabbits cause changes on ECG and that the bacteria interact with platelets and possibly contribute to thromboembolic events [33].

The war-time effects on diet and dental health of Norwegian school children were observed and recorded during World War II in Norway and reported by Toverud et al. $[34,35]$. The reduced availability of sugar and other food commodities coincided with better oral health. Mortality statistics published by Statistics Norway showed the decline of CVD during the war and its increasing trend and that of 
cerebral stroke for several decades during the postwar period when diet and smoking habits changed [36].

\section{The Multifactor Model of Causation}

Discussions on inflammation and infection hypotheses subsided with a few exceptions and the attention rose from the late 1980s $[18,19]$. There was increased attention to how research had been carried out in terms of what proof there was in the different study designs, statistical analysis, and quality and in Hill's framework on causality [37-42]. Rothman presented the causal pie model as a multifactor model which views the joint action of many component factors or component causes [37].

One of the important groundbreaking research enterprises underpinning a multifactor causal model is the Framingham Heart Study [43]. This study started as an endeavour to study heart disease in 1948, when the population, 5209 individuals, of the small city of Framingham in the USA was invited to participate in a health survey. Many of the participants and their offspring have attended repeated health surveys since 1948, providing the researchers and health professionals and health authorities with a wealth of information. To help the clinicians and patients, they developed the renowned Framingham risk score for CVD, based on a multifactor approach. The European Society of Cardiology has developed a risk score, the Euroscore, for calculating the predicted operative mortality for patients undergoing cardiac surgery, a Score risk chart, and HeartScore, an interactive calculator for cardiovascular risk [5].

\section{Clinical Confirmation of Periodontal and Dental Diseases}

Several indexes have been used to diagnose, identify, and grade the level of oral disease and tissue destruction. A list of these would include registration of bacteria in crevicular fluid, sampling plaque, calculus, oral hygiene index, periodontal index, level of gingival margin to the cementoenamel junction, teeth lost, the amount of tooth decay, dentures, status of the oral mucosa and other oral structures, anamnestic features such as pain, oral functionality, and other kinds of discomfort $[17,44,45]$. These measures are in a way surrogates for bacterial exposure. Demmer et al. [46], in the INVEST study, assessed which of a series of periodontal disease status measures were most closely related to the bacterial infections. They found that, after examining the measures of severity and extent of alveolar bone loss, probing depth, and pocket depth, relatively shallow pocket depth should be incorporated. The highest correlations were observed for percentage sites with bleeding on probing (BoP) $(r=0.62)$, percentage sites with pocket depth $\geq 3 \mathrm{~mm}$ $(r=0.61)$, and number of sites with BoP $(r=0.59)$. The validity of self-reported information on periodontal disease has been found to be sufficiently reliable [47]. Results from different studies are reasonably consistent across the different diagnostic modalities used.
Genomic analyses into chronic periodontitis have been performed. Divaris et al. [48] did identify six loci for periodontitis but did not find significant genome-wide signs of association for chronic periodontitis. Successful antiviral treatment of a highly refractory periodontal condition indicates an occasional viral role in periodontitis [15].

Caries is diagnosed by clinical examination and radiographs. If the caries process has progressed to pulpitis, pain is a major symptom, but systemic effects may follow local spread of infection in the mandible or maxilla and the circulation.

\section{Metastatic Infections by Oral Pathogens}

The identification of bacteria or bacterial products in the circulation and in cardiovascular tissues are major and crucial evidence for establishing oral infections as causal for CVDs [49-51]. Infected periodontal tissue and tooth decay can provide entry for bacteria, virus, and fungi into the circulation and facilitate proliferation of microbiota in vascular tissue at or near the infection site or carriage via the bloodstream to distant sites. Bacteria have shown invasive properties into cardiovascular structures such as arterial walls, aortic aneurysms, and heart valves [52, 53]. Viable oral bacteria have been identified in several organs in the body. Apart from being identified pathologically in cardiovascular structures, oral bacteria have been identified in synovial fluid in rheumatoid arthritis, associated with preterm low birth weight, sepsis, obesity, chronic obstructive pulmonary disease, chronic kidney disease, oral and oropharyngeal cancer, and diabetes, although periodontitis is not considered to be causal [44].

Bacterial antigen levels can be identified and detected in serum using several methods such as western blot or enzyme-linked immunoabsorbent assay (ELISA) $[49,50]$. In serum, bacterial DNA can also be identified, as well as a number of inflammatory markers. Pathological examinations have identified oral bacteria in arterial walls, heart valves, atheroma of arteries, and aneurysms [8, 18, 49, 51-53]. The bacteria are identified either as intact specimens or by DNA fragments. Polymerase chain reaction (PCR) analyses are used to identify bacteria that cannot be cultivated [12]. These pathological analyses often reveal nonoral bacteria indicating a wider pathological infectious burden.

Important evidence that CVDs originated from patients' own oral pathogens was shown by Fiehn et al. [54], who established strains of oral microbes in two patients (patient 1, Streptococcus mutans; patient 2, S. oralis or S. mitis) related to infectious endocarditis by isolating streptococcal strains from the oral cavity of patients with streptococcal endocarditis and comparing them biochemically and genetically with their blood samples.

Fiehn et al. [55] have also identified bacterial DNA in atherosclerotic plaque from carotid and femoral arteries removed during surgery, but they did not find viable bacteria. They were able to cultivate Porphyromonas gingivalis, Prevotella intermedia, Prevotella nigrescens, Campylobacter recta, Actinobacillus actinomycetemcomitans, Tannerella 
forsythensis, and oral streptococci. Prevotella intermedia occurred in all samples.

Haraszthy et al. [56] examined specimens obtained during carotid endarterectomy. They tested for Chlamydia pneumoniae, human cytomegalovirus (hCMV), Actinobacillus actinomycetemcomitans, Bacteroides forsythus, Porphyromonas gingivalis, and Prevotella intermedia. Of 50 specimens 36 had oral microbes present, $18 \mathrm{hCMV}$, and $15 \mathrm{Bac}$ teroides forsythus. Often two or more periodontal pathogen species were identified simultaneously.

Kuramitsu et al. [57] have shown that Porphyromonas gingivalis may contribute to foam cell formation in macrophage cultures. Kozarov's [53] overview of bacterial invasion of vascular cells gave an updated insight into many aspects of vascular infectology. He also contributed to the paper by Reyes et al. [58] on the same issue of atherosclerotic pathology. They concluded that there is strong evidence of the ability of periodontal pathogens to contribute to atherosclerosis. They considered that the following first six points of evidence have been established: periodontal bacteria can disseminate from the oral cavity and reach systemic vascular tissues, be found in affected tissues, live within the affected site, invade affected cell types, induce atherosclerosis in animal models of disease, and cause noninvasive mutants of periodontal bacteria to significantly reduce pathology in vitro and in vivo. They did not find that periodontal isolates from human atheromas can cause atherosclerosis in animal models of infection.

\section{Intermediary Factors and Biomarkers for CVD}

A number of studies have looked into intermediary factors associated with increased risk for CVD. The studies range from animal models and microbiology to epigenetic and clinical studies both as patient series or randomized controlled trials. Recent animal studies using ApoE-mice have mapped the effect of several biological markers on atherosclerosis development associated with different oral bacteria. Mice infected with Treponema denticola underwent several reactions to the infection: the bacteria colonized oral cavity and induced alveolar bone resorption, systemic antibody response was observed, and the bacteria colonized atherosclerotic plaque [59]. The inflammatory acute-phase reactant SAA levels did not change, but $T$. denticola chronic infection was associated with changes in known cardiovascular risk factors as VDDL, LDL, and total cholesterol that increased and NO that decreased in infected versus shaminfected mice. Changes were observed in atherosclerotic development-related gene expression such as in genetic expression encoding of coagulation and endothelial cell adhesion. The infection also induced several serum inflammatory mediators. The inoculation by the oral bacteria Porphyromonas gingivalis in mice was associated with alteration in the lipid profile and hence accelerated the formation of atheroma [60]. The infection caused elevation of LDL, VLDL, and total cholesterol and a reduction in serum HDL. A polymicrobial infection of $T$. denticola, $P$. gingivalis, and Tannerella forsythia showed increase in aortic plaque, increased macrophage accumulation, enhanced serum amyloid A, increased serum cholesterol, and triglycerides [61]. These three studies chosen among a number of studies illustrate that systemic inflammation can be initiated by common oral bacteria causative of periodontal infection and can induce several changes in the circulation that induces changes in the vasculature that are very closely related to known processes of cardiovascular disease development.

Carotid artery plaque but not brachial-ankle pulse wave velocity $[45,62-66]$ has been found to be a valid association. Desvarieux et al. [65] report how clinical probing depth and assessment of periodontal bacterial species relate to changes in the carotid intermedia thickness (IMT) during a threeyear average follow-up. Improvement in clinical status and reduced microbial levels were related to a reduced rate of IMT progression.

C-reactive protein (CRP) is a nonspecific inflammatory factor now considered to be associated with acute myocardial infarction [67-71]. CRP was found to be a significant predictor of $\mathrm{CHD}$ in a combined analysis of the Nurses' Health Study and Health Professional Followup Study [71]. Noack et al. [70] have shown, in a study of 174 patients with periodontitis, that CRP is also dose related to the severity of periodontal disease. Porphyromonas gingivalis, Prevotella intermedia, Campylobacter recta, and Bacteroides forsythus were identified in subgingival plaque samples. The effect of CRP as an independent risk factor was not evident after analysis for oral infection by antigens Aggregatibacter actinomycetemcomitans, Tannerella forsythus, Porphyromonas gingivalis, and Treponema denticola in crosssectional analyses of the Oslo II study of men, adjusted for known CVD risk factors, Framingham risk factors [50]. The risk of oral pathogens for myocardial infarction had an odds ratio of 1.30 (95\% CI 1.01-1.68). Elevated levels of CRP were found to be associated with several systemic disorders in men such as osteoporosis, asthma, fibromyalgia/chronic fatigue syndrome, diabetes, chronic bronchitis/emphysema, and myocardial infarction: self-reported information [72].

The role of lipoproteins and lipoprotein metabolism in periodontal disease has been evaluated because these are important in the development and prediction of CVDs $[73,74]$. These studies indicated that periodontal disease treatment influences lipid metabolism. Pussinen et al. [73] put forward evidence for a higher high-density lipoprotein(HDL-) mediated cholesterol efflux from the liver in the course of periodontal treatment. HDL is considered to be an antiatherogenic lipoprotein because it neutralizes lipopolysaccharide (LPS) in the circulation and protects lowdensity lipoprotein (LDL) against oxidation, as well as having a role in reverse cholesterol transport.

It is evident that biomarkers and systemic mediators are related to both periodontal disease and CVDs through their effect on inflammatory processes and thrombotic and haemostatic markers or mediators [75]. The list of inflammatory mediators established from intervention studies is CRP, fibrinogen, IL-6, haptoglobin, IL-18, IL-4, serum amyloid A, $\alpha_{1}$-chymotrypsin, matrix metalloprotease-9, plateletactivating factor (PAF), and PAF acetyl hydrolase (AH). 
An equivalent list for thrombotic or haemostatic markers is plasminogen activator inhibitor-1 (PAI)-1, fibrinogen, von Willebrand's factor, sP-selectin, P-selectin, CD18, and activated glycoprotein IIb/IIIa (platelet activation marker).

\section{Immunological Response and Bacterial Toxins}

The development of periodontal disease is strongly related to the immunological response and the bacterial products that are damaging to the health of the periodontium. The defence against infections is facilitated by the innate and adaptive immune systems [12]. If a pathogen manages to penetrate the outer layers of defence and the mucosal epithelium and underlying structures, the innate immune system reacts. A sequence of known pathological reactions occurs. Production of acute phase protein in response to infections such as Creactive protein (CRP), as surrogate biomarkers for infections produced by the liver, has been found to be associated with CVD $[76,77]$. Other inflammatory markers are IL-1 $\beta$, IL6 , TNF- $\alpha$, and the prostaglandin $\mathrm{PGE}_{2}$ which are produced locally in inflamed gingival and periodontal tissue, which are released into the circulation in the course of an infection [12].

Different bacteria live in aerobic, anaerobic, or facultative anaerobic environments within oral biofilms [12] and in the gingival crevice; oral mucosa of the cheek and tongue protects and provides a substrate for each bacterium, virus, or fungus. Bacterial and viral pathogens involve colonization, multiplication, and invasion. Antibodies to periopathogens have been identified in serum related to active subgingival colonisation of bacteria [78].

Bacteria can produce exotoxins and endotoxins, the former being secreted by bacteria and being highly toxic [12]. Examples are Staphylococcus aureus and Aggregatibacter actinomycetemcomitans that target leukocytes. Endotoxins are an integral part of the bacterial cell wall. LPS from the breakdown of the bacterial wall of Gram-negative bacteria is the most important endotoxin in the circulation. Oral bacteria produce several tissue-damaging enzymes. It is thus plausible for oral infectious agents to be directly involved in pathological processes in the cardiovascular system. This review does not give a full coverage of this expanding field but acknowledges the importance of immunological response and bacterial toxins to be of great importance not only for the development of oral infections per se but to the systemic changes that have been demonstrated in a variety of studies.

\section{Periodontal Therapy and Its Effect on CVD Risk Factor Profile}

Periodontal therapy influences cardiovascular endothelial dysfunction, the levels of inflammatory markers, and several other serum markers. The systematic review by Moura Foz et al. [79] in 2010 identified 836 references and included 9 studies. Inclusion criteria were randomized controlled trial (RCT) or cohort studies, patients who had undergone a full mouth periodontal examination, and adults only. The studies reported a measure of association between periodontal disease and atherosclerosis, characterized by high levels of inflammatory markers or endothelial dysfunction. The intervention was standardized periodontal therapy or intensive periodontal therapy including adjunctive use of antibiotic therapy. Three studies on CRP were selected for meta-analysis and they showed a significant reduction in CRP of 0.50 $\mathrm{mg} / \mathrm{mL}$ (96\% CI 0.15-0.85).

The systematic review by D'Aiuto et al. [77] in 2013 of RCTs had the following inclusion criteria for the study on effect of treatment on periodontitis and CVD: control treatment without surgical or nonsurgical therapy and active treatment including scaling and root planing. However, they could also include surgical therapy, extractions, and antibiotic treatment. All participants had periodontitis. The follow-up time ranged from 6 weeks to 24 weeks, and studies had similar response variables. Fourteen studies were included and the variation in clinical outcomes illustrates this field. The level of evidence was moderate for lipids (multiple), endothelial function (multiple measures), and multiple cytokines. Limited evidence was found for blood pressure, white blood cell count, acute phase reactants, multiple haemostatic factors, matrix metalloproteases, and oxidative stress. The authors concluded that periodontal therapy triggered a short-term inflammatory response but gave a further reduction in the systemic inflammatory markers and improvement in endothelial function.

Up to the present time, there has been no study to confirm the effect of prophylactic pretreatment antibiotic use in patients at risk of infectious endocarditis [80, 81]. Consequently, the National Institute for Health and Care Excellence (NICE 2011) of the British National Health Service (NHS) advises clinicians not to use antibiotic prophylaxis in dental treatment or other treatments that have a risk of bacteraemia. The reason for this is that transient bacteraemia can occur during tooth brushing and eating [82].

\section{Incidence and Mortality of CVD Associated with Oral Infections}

In prospective studies on incident and mortality on CVD oral infection has been categorized according to tooth brushing [82] or tooth extractions [83-85], being either self-reported [86] or clinically confirmed periodontitis or gingivitis [77, 87], genetic associations [85], or simultaneous oral disease factors of dental plaque, calculus, gingival inflammation and number of missing molars [86].

Which CVD diagnoses have been included as study outcome varies between studies. The Scottish Health Study incorporated acute myocardial infarction, coronary artery bypass, percutaneous coronary angioplasty, stroke, and heart failure [82, 84]. The US Department of Veteran Affairs (VA) Normative Study (NAS) included incident CHD as angina, myocardial infarction, or fatal CHD [83]. US Male Physicians Study reported risk for nonfatal myocardial infarction, nonfatal stroke, and cardiovascular deaths separately [86]. The First National Health and Nutrition Examination Survey Epidemiologic Follow-up Study (NHANES I) reported as main outcome the first occurrence of hospitalization due to 
CHD, death from CHD, or revascularization procedures [87]. Söder et al. observed an association between periodontitis and premature death in a 16-year follow-up study of a Swedish population [88].

In prospective cohorts, stroke incidence has been found to be related to periodontal disease [89], tooth loss [90] history of periodontal disease but not current periodontal disease [91], and severe periodontal disease for recurrent events [92]. A recent study found dental prophylaxis and periodontal treatment to be protective factors to ischaemic [93].

Incident tooth loss has been found to be associated with peripheral arterial disease in a 12-year follow-up: history of periodontal disease RR 1.41 (95\% CI 1.12-1.77), any tooth loss during follow-up RR 1.39 (95\% CI 1.07-1.82) [94].

Dietrich et al. [95] identified 11 studies in their systematic review for clinically and radiographically diagnosed periodontal disease predicting atherosclerotic CVD, including CVD, cerebrovascular disease, and peripheral arterial disease. They concluded that there was evidence for some groups of patients with periodontal disease, but not all the subgroups studied. There was also insufficient evidence for secondary CVD events.

Not all prospective studies confirmed any association. Tuominen et al. [96] did not find that oral health indicators predicted CVD deaths in a 12-year follow-up period. They concluded after looking at oral health data from a clinical examination of caries, periodontal and dental plaque status, presence of remaining teeth, and various types of dentures that the effect on CHD was mostly confounded especially by factors relating to health behaviour. Linden et al. [97] looked into the different criteria used that constituted periodontal disease in different studies and advised that a consensus be reached for future studies. The strength of evidence was also related to study design and two important studies were casecontrol and cohort studies.

The PAVE study of periodontal infection and secondary vascular events, a pilot randomized controlled trial, was unsuccessful as $48 \%$ of the control group received preventive or periodontal treatment [98]. Antibiotic therapy trials in response to infections by Chlamydia pneumoniae have been unsuccessful in preventing secondary vascular events [99].

\section{Closing Remarks}

In the pursuit of understanding cardiovascular disease (CVD) occurrence, there is now strong interest in oral infections as part of the causal pathway for cardiovascular diseases. There is much evidence across disciplines from basic science including microbiology and genetics, pathology, and prospective studies on oral health parameters associated with incidence and mortality of CVD through clinical trials for the effect of treatment of oral infections on reducing the level of CVD biomarkers in both primary and secondary prevention. The infection hypothesis has been tested for several CVD outcomes separately or as composite outcomes. A range of different diagnostic measures of disease has been used. The effect of periodontal treatment has been evaluated against known CVD biological markers. The presence of a range of bacteria and viruses has been detected in serum and CVD structures. These results indicate a scope for prevention of CVD through the already well-established advice for optimal oral health.

Further research is needed to establish the effect of treating oral infections to prevent CVD using a randomized controlled study design with a sufficiently long follow-up for incidence and mortality of CVD. Basic science studies are needed to extend our knowledge on biological mechanisms and prospective studies on oral infections predicting incidence and mortality from CVD, to provide the sufficient cross evidence.

\section{Conflict of Interests}

The author declares that there is no conflict of interests regarding the publication of this paper.

\section{References}

[1] World Health Organization, http://www.who.int/research/en/.

[2] P. E. Petersen and H. Ogawa, "Strengthening the prevention of periodontal disease: the WHO approach," Journal of Periodontology, vol. 76, no. 12, pp. 2187-2193, 2005.

[3] J. Chen, S. L. T. Normand, Y. Wang, E. E. Drye, G. C. Schreiner, and H. M. Krumholz, "Recent declines in hospitalizations for acute myocardial infarction for medicare fee-for-service beneficiaries: progress and continuing challenges," Circulation, vol. 121, no. 11, pp. 1322-1328, 2010.

[4] L. L. Håheim, I. Holme, I. Hjermann, P. Leren, and S. Tonstad, "Trends in the incidence of acute myocardial infarction and stroke: a 21-year follow-up of the Oslo study," Scandinavian Cardiovascular Journal, vol. 38, no. 4, pp. 216-221, 2004.

[5] L. B. Goldstein, R. Adams, M. J. Alberts et al., "Primary prevention of ischemic stroke: a guideline from the American Heart Association/American Stroke Association Stroke Council," Stroke, vol. 37, no. 6, pp. 1583-1633, 2006, Erratum in Stroke, vol. 38 , no. 1, p. $207,2007$.

[6] http://www.escardio.org/Pages/index.aspx.

[7] J. A. Berliner, M. Navab, A. M. Fogelman et al., "Atherosclerosis: basic mechanisms: oxidation, inflammation, and genetics," Circulation, vol. 91, no. 9, pp. 2488-2496, 1995.

[8] R. Ross, "Aterosclerosis-an inflammatory disease," The New England Journal of Medicine, vol. 340, pp. 115-126, 1999.

[9] P. Libby, P. M. Ridker, and G. K. Hansson, "Inflammation in atherosclerosis: From pathophysiology to practice," Journal of the American College of Cardiology, vol. 54, no. 23, pp. 21292138, 2009.

[10] S. Kerrigan and D. Cox, "Biological mechanisms: platelets and bacteria-current scientific evidence and methods of analyses," in Oral Infections and Cardiovascular Disease, vol. 6, chapter 6, pp. 45-66, Bentham Science, New York, NY, USA, 2011.

[11] S. O'Connor, C. Taylor, L. A. Campbell, S. Epstein, and P. Libby, "Potential infectious etiologies of atherosclerosis: a multifactorial perspective," Emerging Infectious Diseases, vol. 7, no. 5, pp. 780-788, 2001.

[12] G. Dahlén, N.-E. Fiehn, I. Olsen, and U. Dahlgren, Oral Microbiology and Immunology, Munksgaard, Copenhagen, Denmark, 2012. 
[13] P. I. Eke, B. A. Dye, L. Wei, G. O. Thornton-Evans, and R. J. Genco, "Prevalence of periodontitis in adults in the united states: 2009 and 2010," Journal of Dental Research, vol. 91, no. 10, pp. 914-920, 2012.

[14] B. J. Paster, I. Olsen, J. A. Aas, and F. E. Dewhirst, "The breadth of bacterial diversity in the human periodontal pocket and other oral sites," Periodontology, vol. 42, no. 1, pp. 80-87, 2006.

[15] B. Grinde and I. Olsen, "The role of viruses in oral disease," Journal of Oral Microbiology, vol. 2, article 2127, 2010.

[16] M. Enersen, "Risk factors for periodontal disease," in Oral Infections and Cardiovascular Disease, chapter 5, Bentham Science, New York, NY, USA, 2011.

[17] F. DeStefano, R. F. Anda, H. S. Kahn, D. F. Williamson, and C. M. Russell, "Dental disease and risk of coronary heart disease and mortality," British Medical Journal, vol. 306, no. 6879, pp. 688-691, 1993.

[18] R. Rautemaa, A. Lauhio, M. P. Cullinan, and G. J. Seymour, "Oral infections and systemic disease-an emerging problem in medicine," Clinical Microbiology and Infection, vol. 13, no. 11, pp. 1041-1047, 2007.

[19] G. J. Seymour, P. J. Ford, M. P. Cullinan, S. Leishman, and K. Yamazaki, "Relationship between periodontal infections and systemic disease," Clinical Microbiology and Infection, vol. 13, supplement 4, pp. 3-10, 2007.

[20] X. Li, K. M. Kolltveit, L. Tronstad, and I. Olsen, "Systemic diseases caused by oral infection," Clinical Microbiology Reviews, vol. 13, no. 4, pp. 547-558, 2000.

[21] S. Engebretson and T. Kocher, "Evidence that periodontal treatment improves diabetes outcomes: a systematic review and meta-analysis," Journal of Clinical Periodontology, vol. 40, no. 14, pp. S153-S163, 2013.

[22] W. S. Borgnakke, P. V. Ylöstalo, G. W. Taylor, and R. J. Genco, "Effect of periodontal disease on diabetes: systematic review of epidemiologic observational evidence," Journal of Clinical Periodontology, vol. 40, no. 14, pp. S135-S152, 2013.

[23] M. Ide and P. N. Papapanou, "Epidemiology of association between maternal periodontal disease and adverse pregnancy outcomes-Systematic review," Journal of Clinical Periodontology, vol. 40, supplement 14, pp. S181-S194, 2013.

[24] B. S. Michalowicz, A. Gustafsson, V. Thumbigere-Math, and K. Buhlin, "The effects of periodontal treatment on pregnancy outcomes," Journal of Clinical Periodontology, vol. 40, no. 14, pp. S195-S208, 2013.

[25] A. A. Bahekar, S. Singh, S. Saha, J. Molnar, and R. Arora, "The prevalence and incidence of coronary heart disease is significantly increased in periodontitis: a meta-analysis," American Heart Journal, vol. 154, no. 5, pp. 830-837, 2007.

[26] S. Fedele, W. Sabbah, N. Donos, S. Porter, and F. D'Aiuto, "Common oral mucosal diseases, systemic inflammation, and cardiovascular diseases in a large cross-sectional US survey," The American Heart Journal, vol. 161, no. 2, pp. 344-350, 2011.

[27] M. Kebschull, R. T. Demmer, and P. N. Papapanou, "Gum bug, leave my heart alone!'-epidemiologic and mechanistic evidence linking periodontal infections and atherosclerosis," Journal of Dental Research, vol. 89, no. 9, pp. 879-902, 2010.

[28] M. Helfand, D. I. Buckley, M. Freeman et al., "Emerging risk factors for coronary heart disease: a summary of systematic reviews conducted for the U.S. Preventive Services Task Force," Annals of Internal Medicine, vol. 151, no. 7, pp. 496-507, 2009.

[29] L. L. Håheim, Oral Infections and Cardiovascular Disease, Bentham Science Publishers, New York, NY, USA, 2011.
[30] M. S. Tonetti and T. E. van Dyke, "Periodontitis and atherosclerotic cardiovascular disease: consensus report of the Joint EFP/AAP Workshop on Periodontitis and Systemic Diseases," Journal of Clinical Periodontology, vol. 40, no. 14, pp. S24-S29, 2013.

[31] F. J. Nieto, "Infections and atherosclerosis: new clues from an old hypothesis?" American Journal of Epidemiology, vol. 148, no. 10, pp. 937-948, 1998.

[32] K. Mattila, "Dental infections and cardiovascular disease-the early findings," in Oral Infections and Cardiovascular Disease, chapter 1, pp. 3-7, Bentham Science, New York, NY, USA, 2011.

[33] M. C. Herzberg and M. W. Weyer, "Dental plaque, platelets, and cardiovascular diseases," Annals of Periodontology, vol. 3, no. 1, pp. 151-160, 1998.

[34] G. Toverud, L. Rubal, and D. G. Wiehl, "The influence of war and postwar conditions on the teeth of Norwegian school children," Milbank Memorial Fund Quarterly, vol. 39, pp. 489$539,1961$.

[35] G. Toverud, "The influence of war and post-war conditions on the teeth of Norwegian school children. III. Discussion of food supply and dental condition in Norway and other European countries," The Milbank Memorial Fund Quarterly, vol. 35, no. 4, pp. 373-459, 1957.

[36] Statistics Norway, http://www.ssb.no/en/forside;jsessionid= F735889A891792F079DEF53DAB5626EB.kpld-as-prod03.

[37] K. Rothman, Epidemiology:: An Introduction, Oxford University Press, Oxford, UK, 2nd edition, 2012.

[38] A. B. Hill, "The environment and disease: association or causation?" Proceedings of the Royal Society of Medicine, vol. 58, pp. 295-300, 1965.

[39] K. Joshipura, J. C. Zevallos, and C. S. Ritchie, "Strength of evidence relating periodontal disease and atherosclerotic disease," Compendium of Continuing Education in Dentistry, vol. 30, no. 7, pp. 430-439, 2009.

[40] W. B. Grant and B. J. Boucher, "Are hill's criteria for causality satisfied for vitamin D and periodontal disease?" DermatoEndocrinology, vol. 2, no. 1, pp. 30-36, 2010.

[41] S. Yusuf and S. Anand, "Deciphering the causes of cardiovascular and other complex diseases in populations: achievements, challenges, opportunities, and approaches," Progress in Cardiovascular Diseases, vol. 53, no. 1, pp. 62-67, 2010.

[42] J. Hyman, "The importance of assessing confounding and effect modification in research involving periodontal disease and systemic diseases," Journal of Clinical Periodontology, vol. 33, no. 2, pp. 102-103, 2006.

[43] M. J. Pencina, R. B. D’Agostino, M. G. Larson, J. M. Massaro, and R. S. Vasan, "Predicting the 30-year risk of cardiovascular disease: the framingham heart study," Circulation, vol. 119, no. 24, pp. 3078-3084, 2009.

[44] G. J. Linden and M. C. Herzberg, "Periodontitis and systemic diseases: a record of discussions of working group 4 of the Joint EFP/AAP Workshop on Periodontitis and Systemic Diseases," Journal of Clinical Periodontology, vol. 40, no. 14, pp. S20-S23, 2013.

[45] M. Desvarieux, R. T. Demmer, T. Rundek et al., "Relationship between periodontal disease, tooth loss, and carotid artery plaque: the oral infections and vascular disease epidemiology study (INVEST)," Stroke, vol. 34, no. 9, pp. 2120-2125, 2003.

[46] R. T. Demmer, P. N. Papapanou, D. R. Jacobs, and M. Desvarieux, "Evaluating clinical periodontal measures as surrogates 
for bacterial exposure: the Oral Infections and Vascular Disease Epidemiology Study (INVEST)," BMC Medical Research Methodology, vol. 10, article 2, 2010.

[47] K. Buhlin, A. Gustafsson, K. Andersson, J. Håkansson, and B. Klinge, "Validity and limitations of self-reported periodontal health," Community Dentistry and Oral Epidemiology, vol. 30, no. 6, pp. 431-437, 2002.

[48] K. Divaris, K. L. Monda, K. E. North et al., "Exploring the genetic basis of chronic periodontitis: a genome-wide association study," Human Molecular Genetics, vol. 22, no. 11, pp. 23122324, 2013.

[49] T. E. van Dyke and A. J. van Winkelhoff, "Infection and inflammatory mechanisms," Journal of Clinical Periodontology, vol. 40, no. 14, pp. S1-S7, 2013.

[50] L. Lund Håheim, I. Olsen, P. Nafstad, P. Schwarze, and K. S. Rønningen, "Antibody levels to single bacteria or in combination evaluated against myocardial infarction," Journal of Clinical Periodontology, vol. 35, no. 6, pp. 473-478, 2008.

[51] J. D. Beck, P. Eke, G. Heiss et al., "Periodontal disease and coronary heart disease: a reappraisal of the exposure," Circulation, vol. 112, no. 1, pp. 19-24, 2005.

[52] I. Olsen, "Oral bacteria in cardiovascular diseases," in Oral Infections and Cardiovascular Disease, chapter 5, pp. 35-44, Bentham Science Publishers, New York, NY, USA, 2011.

[53] E. Kozarov, "Bacterial invasion of vascular cell types: vascular infectology and atherogenesis," Future Cardiology, vol. 8, no. 1, pp. 123-138, 2012.

[54] N.-E. Fiehn, E. Gutschik, T. Larsen, and J. M. Bangsborg, "Identity of streptococcal blood isolates and oral isolates from two patients with infective endocarditis," Journal of Clinical Microbiology, vol. 33, no. 5, pp. 1399-1401, 1995.

[55] N.-E. Fiehn, T. Larsen, N. Christiansen, P. Holmstrup, and T. V. Schroeder, "Identification of periodontal pathogens in atherosclerotic vessels," Journal of Periodontology, vol. 76, no. 5, pp. 731-736, 2005.

[56] V. I. Haraszthy, J. J. Zambon, M. Trevisan, M. Zeid, and R. J. Genco, "Identification of periodontal pathogens in atheromatous plaques," Journal of Periodontology, vol. 71, no. 10, pp. 15541560, 2000.

[57] H. K. Kuramitsu, I.-C. Kang, and M. Qi, "Interactions of porphyromonas gingivalis with host cells: implications for cardiovascular diseases," Journal of Periodontology, vol. 74, no. 1, pp. 85-89, 2003.

[58] L. Reyes, D. Herrera, E. Kozarov, S. Roldán, and A. ProgulskeFox, "Periodontal bacterial invasion and infection: contribution to atherosclerotic pathology," Journal of Clinical Periodontology, vol. 40, no. 14 supplement, pp. S30-S50, 2013.

[59] S. S. Chukkapalli, M. F. Rivera, I. M. Velsko et al., "Invasion of oral and aortic tissues by oral spirochete Treponema denticola in ApoE-/- mice causally links periodontal disease and atherosclerosis," Infection and Immunity, vol. 82, no. 5, pp. 19591967, 2014.

[60] T. Maekawa, N. Takahashi, K. Tabeta et al., "Chronic oral infection with porphyromonas gingivalis accelerates atheroma formation by shifting the lipid profile," PLoS ONE, vol. 6, no. 5, Article ID e20240, 2011.

[61] M. F. Rivera, J.-Y. Lee, M. Aneja et al., "Polymicrobial infection with major periodontal pathogens induced periodontal disease and aortic atherosclerosis in hyperlipidemic ApoE ${ }^{\text {null }}$ mice," PLoS ONE, vol. 8, no. 2, Article ID e57178, 2013.
[62] S. P. Engebretson, I. B. Lamster, M. S. V. Elkind et al., "Radiographic measures of chronic periodontitis and carotid artery plaque," Stroke, vol. 36, no. 3, pp. 561-566, 2005.

[63] M. Desvarieux, R. T. Demmer, T. Rundek et al., "Periodontal microbiota and carotid intima-media thickness: the Oral Infections and Vascular Disease Epidemiology Study (INVEST)," Circulation, vol. 111, no. 5, pp. 576-582, 2005.

[64] M. Desvarieux, R. T. Demmer, D. R. Jacobs Jr. et al., "Periodontal bacteria and hypertension: the oral infections and vascular disease epidemiology study (INVEST)," Journal of Hypertension, vol. 28, no. 7, pp. 1413-1421, 2010.

[65] M. Desvarieux, R. T. Demmer, D. R. Jacobs, P. N. Papapanou, R. L. Sacco, and T. Rundek, "Changes in clinical and microbiological periodontal profiles relate to progression of carotid intima-media thickness: the oral infections and vascular disease epidemiology study," Journal of the American Heart Association, vol. 2, Article ID e000254, 2013.

[66] K. Miyaki, K. Masaki, M. Naito et al., "Periodontal disease and atherosclerosis from the viewpoint of the relationship between community periodontal index of treatment needs and brachialankle pulse wave velocity," BMC Public Health, vol. 6, article 131, 2006.

[67] T. Wu, M. Trevisan, R. J. Genco, K. L. Falkner, J. P. Dorn, and C. T. Sempos, "Examination of the relation between periodontal health status and cardiovascular risk factors: serum total and high density lipoprotein cholesterol, C-reactive protein, and plasma fibrinogen," The American Journal of Epidemiology, vol. 151, no. 3, pp. 273-282, 2000.

[68] P. M. Ridker, S. S. Bassuk, and P. P. Toth, "C-reactive protein and risk of cardiovascular disease: evidence and clinical application," Current Atherosclerosis Reports, vol. 5, no. 5, pp. 341-349, 2003.

[69] E. T. H. Yeh and R. P. Palusinski, "C-reactive protein: the pawn has been promoted to queen," Current Atherosclerosis Reports, vol. 5, no. 2, pp. 101-105, 2003.

[70] B. Noack, R. J. Genco, M. Trevisan, S. Grossi, J. J. Zambon, and E. de Nardin, "Periodontal infections contribute to elevated systemic C-reactive protien level," Journal of Periodontology, vol. 72, no. 9, pp. 1221-1227, 2001.

[71] J. K. Pai, T. Pischon, J. Ma et al., "Inflammatory markers and the risk of coronary heart disease in men and women," The New England Journal of Medicine, vol. 351, no. 25, pp. 2599-2610, 2004.

[72] L. Lund Håheim, P. Nafstad, I. Olsen, P. Schwarze, and K. S. Rønningen, "C-reactive protein variations for different chronic somatic disorders," Scandinavian Journal of Public Health, vol. 37, no. 6, pp. 640-646, 2009.

[73] P. J. Pussinen, M. Jauhiainen, T. Vilkuna-Rautiainen et al., "Periodontitis decreases the antiatherogenic potency of high density lipoprotein," Journal of Lipid Research, vol. 45, no. 1, pp. 139-147, 2004.

[74] R. Griffiths and S. Barbour, "Lipoproteins and lipoprotein metabolism in periodontal disease," Clinical Lipidology, vol. 5, no. 3, pp. 397-411, 2010.

[75] H. A. Schenkein and B. G. Loos, "Inflammatory mechanisms linking periodontal diseases to cardiovascular diseases," Journal of Clinical Periodontology, vol. 40, no. 14, pp. S51-S69, 2013.

[76] P. M. Ridker, E. Danielson, F. A. H. Fonseca et al., "Rosuvastatin to prevent vascular events in men and women with elevated Creactive protein," The New England Journal of Medicine, vol. 359, no. 21, pp. 2195-2207, 2008. 
[77] F. D’Aiuto, M. Orlandi, and J. C. Gunsolley, "Evidence that periodontal treatment improves biomarkers and CVD outcomes," Journal of Clinical Periodontology, vol. 40, no. 14, pp. S85-S105, 2013.

[78] J. L. Ebersole, M. A. Taubman, D. J. Smith, D. E. Frey, A. D. Haffajee, and S. S. Socransky, "Human serum antibody responses to oral microorganisms. IV. Correlation with homologous infection," Oral Microbiology and Immunology, vol. 2, no. 2, pp. 53-59, 1987.

[79] A. Moura Foz, G. Alexandre Romito, C. Manoel Bispo et al., "Periodontal therapy and biomarkers related to cardiovascular risk," Minerva Stomatologica, vol. 59, no. 5, pp. 271-283, 2010.

[80] B. Hoen and X. Duval, "Infective endocarditis," New England Journal of Medicine, vol. 369, no. 8, p. 785, 2013.

[81] M. H. Thornhill, M. J. Dayer, J. M. Forde et al., "Impact of the NICE guideline recommending cessation of antibiotic prophylaxis for prevention of infective endocarditis: before and after study," British Medical Journal, vol. 342, no. 7807, Article ID d2392, 2011.

[82] C. de Oliveira, R. Watt, and M. Hamer, "Toothbrushing, inflammation, and risk of cardiovascular disease: results from Scottish Health Survey," BMJ: British Medical Journal, vol. 340, Article ID c2451, 2010.

[83] T. Dietrich, M. Jimenez, E. A. K. Kaye, P. S. Vokonas, and R. I. Garcia, "Age-dependent associations between chronic periodontitis/edentulism and risk of coronary heart disease," Circulation, vol. 117, no. 13, pp. 1668-1674, 2008.

[84] R. G. Watt, G. Tsakos, C. de Oliveira, and M. Hamer, "Tooth loss and cardiovascular disease mortality risk-results from the Scottish Health Survey," PLoS ONE, vol. 7, no. 2, Article ID e30797, 2012.

[85] L. A. Mucci, C.-C. Hsieh, P. L. Williams et al., "Do genetic factors explain the association between poor oral health and cardiovascular disease? A prospective study among Swedish twins," The American Journal of Epidemiology, vol. 170, no. 5, pp. 615-621, 2009.

[86] T. H. Howell, P. M. Ridker, U. A. Ajani, C. H. Hennekens, and W. G. Christen, "Periodontal disease and risk of subsequent cardiovascular disease in U.S. male physicians," Journal of the American College of Cardiology, vol. 37, no. 2, pp. 445-450, 2001.

[87] P. P. Hujoel, M. Drangsholt, C. Spiekerman, and T. A. DeRouen, "Periodontal disease and coronary heart disease risk," Journal of the American Medical Association, vol. 284, no. 11, pp. 1406-1410, 2000.

[88] B. Söder, L. J. Jin, B. Klinge, and P.-Ö. Söder, "Periodontitis and premature death: a 16-year longitudinal study in a Swedish urban population," Journal of Periodontal Research, vol. 42, no. 4, pp. 361-366, 2007.

[89] T. Wu, M. Trevisan, R. J. Genco, J. P. Dorn, K. L. Falkner, and C. T. Sempos, "Periodontal disease and risk of cerebrovascular disease: the First National Health and Nutrition Examination Survey and its follow-up study," Archives of Internal Medicine, vol. 160, no. 18, pp. 2749-2755, 2000.

[90] K. J. Joshipura, H.-C. Hung, E. B. Rimm, W. C. Willett, and A. Ascherio, "Periodontal disease, tooth loss, and incidence of ischemic stroke," Stroke, vol. 34, no. 1, pp. 47-52, 2003.

[91] M. Jimenez, E. A. Krall, R. I. Garcia, P. S. Vokonas, and T. Dietrich, "Periodontitis and incidence of cerebrovascular disease in men," Annals of Neurology, vol. 66, no. 4, pp. 505-512, 2009.

[92] S. Sen, R. Sumner, J. Hardin et al., "Periodontal disease and recurrent vascular events in stroke/transient ischemic attack patients," Journal of Stroke and Cerebrovascular Diseases, vol. 22, no. 8, pp. 1420-1427, 2013.

[93] Y.-L. Lee, H.-Y. Hu, N. Huang, D.-K. Hwang, P. Chou, and D. Chu, "Dental prophylaxis and periodontal treatment are protective factors to ischemic stroke," Stroke, vol. 44, no. 4, pp. 1026-1030, 2013.

[94] H. C. Hung, W. Willett, A. Merchant, B. A. Rosner, A. Ascherio, and K. J. Joshipura, "Oral health and peripheral arterial disease," Circulation, vol. 107, no. 8, pp. 1152-1157, 2003.

[95] T. Dietrich, P. Sharma, C. Walter, P. Weston, and J. Beck, “The epidemiological evidence behind the association between periodontitis and incident atherosclerotic cardiovascular disease," Journal of Clinical Periodontology, vol. 40, supplement 14, pp. S70-S85, 2013, Erratum in Journal of Clinical Periodontology, vol. 40, supplement 14, pp. S210-S215, 2013.

[96] R. Tuominen, A. Reunanen, M. Paunio, I. Paunio, and A. Aromaa, "Oral health indicators poorly predict coronary heart disease deaths," Journal of Dental Research, vol. 82, no. 9, pp. 713-718, 2003.

[97] G. J. Linden, A. Lyons, and F. A. Scannapieco, "Periodontal systemic associations: review of the evidence," Journal of Clinical Periodontology, vol. 40, no. 14, pp. S8-S19, 2013.

[98] S. Offenbacher, J. D. Beck, K. Moss et al., "Results from the Periodontitis and Vascular Events (PAVE) study: a pilot multicentered, randomized, controlled trial to study effects of periodontal therapy in a secondary prevention model of cardiovascular disease," Journal of Periodontology, vol. 80, no. 2, pp. 190-201, 2009.

[99] M. P. Gabay, R. Jain, J. F. Feliu, and A. Marcotte, "Role of antibiotics for the prevention of cardiovascular disease," Annals of Pharmacotherapy, vol. 36, no. 10, pp. 1629-1636, 2002. 


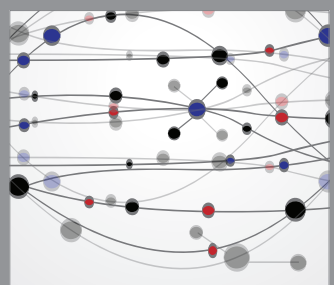

The Scientific World Journal
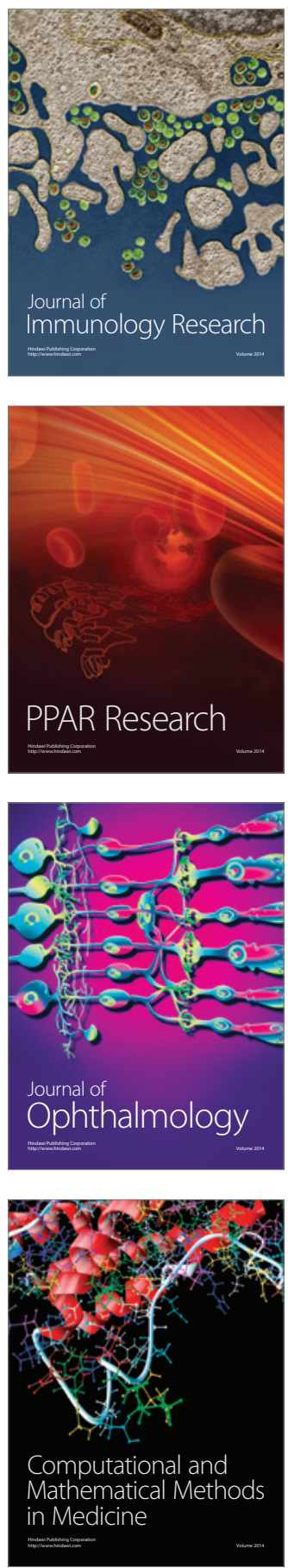

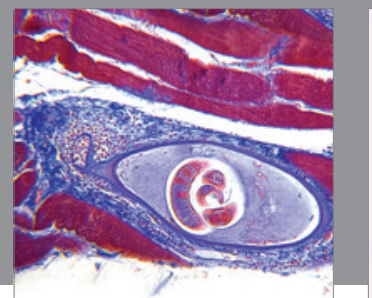

Gastroenterology

Research and Practice
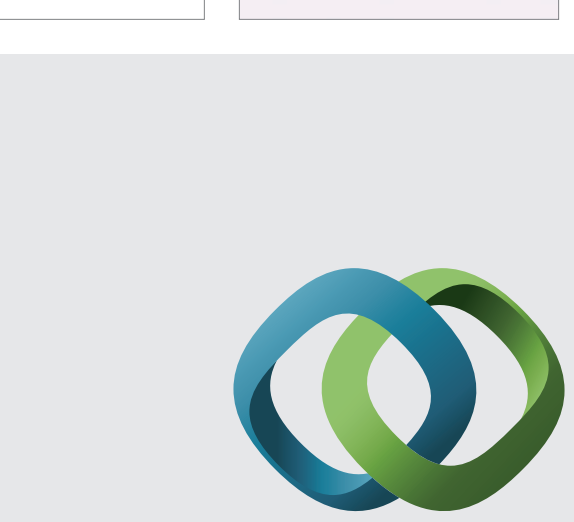

\section{Hindawi}

Submit your manuscripts at

http://www.hindawi.com
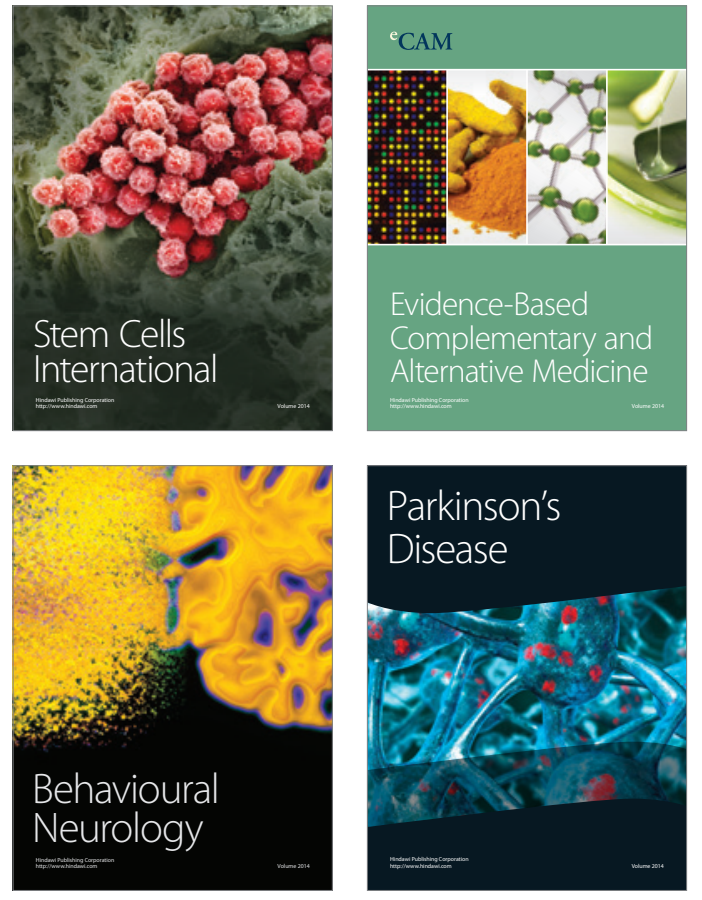
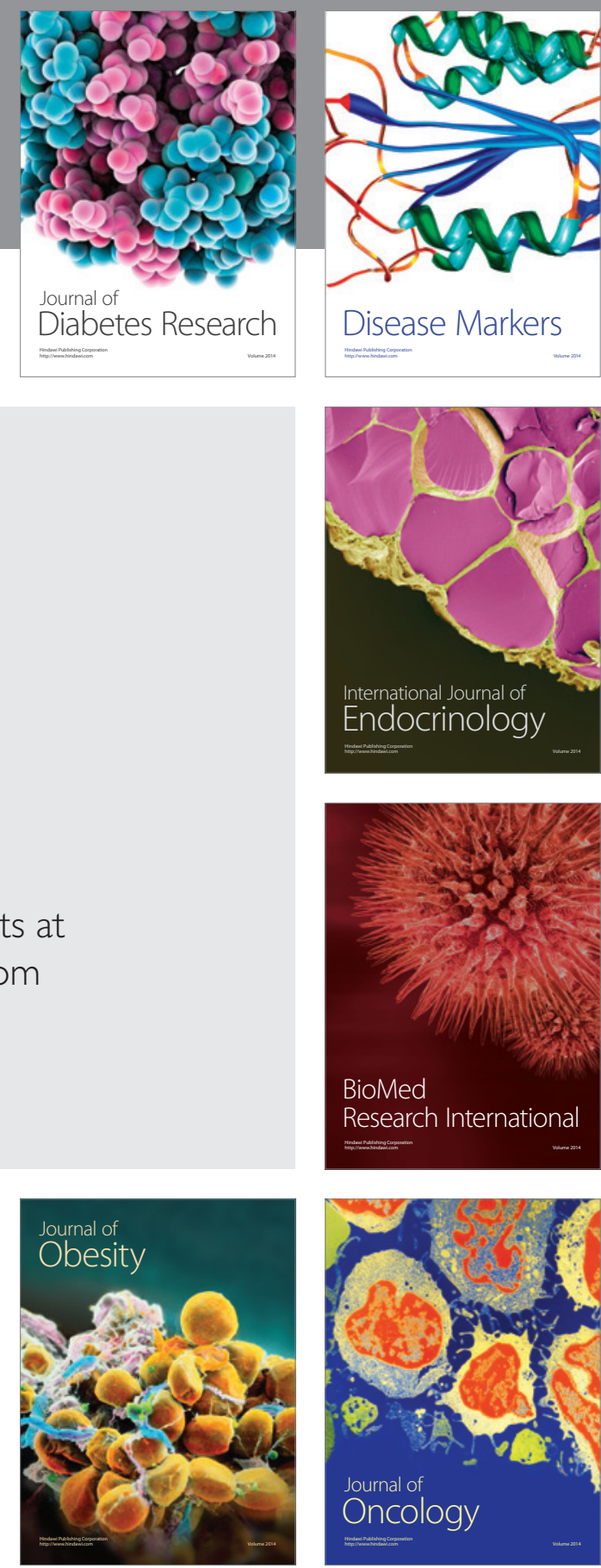

Disease Markers
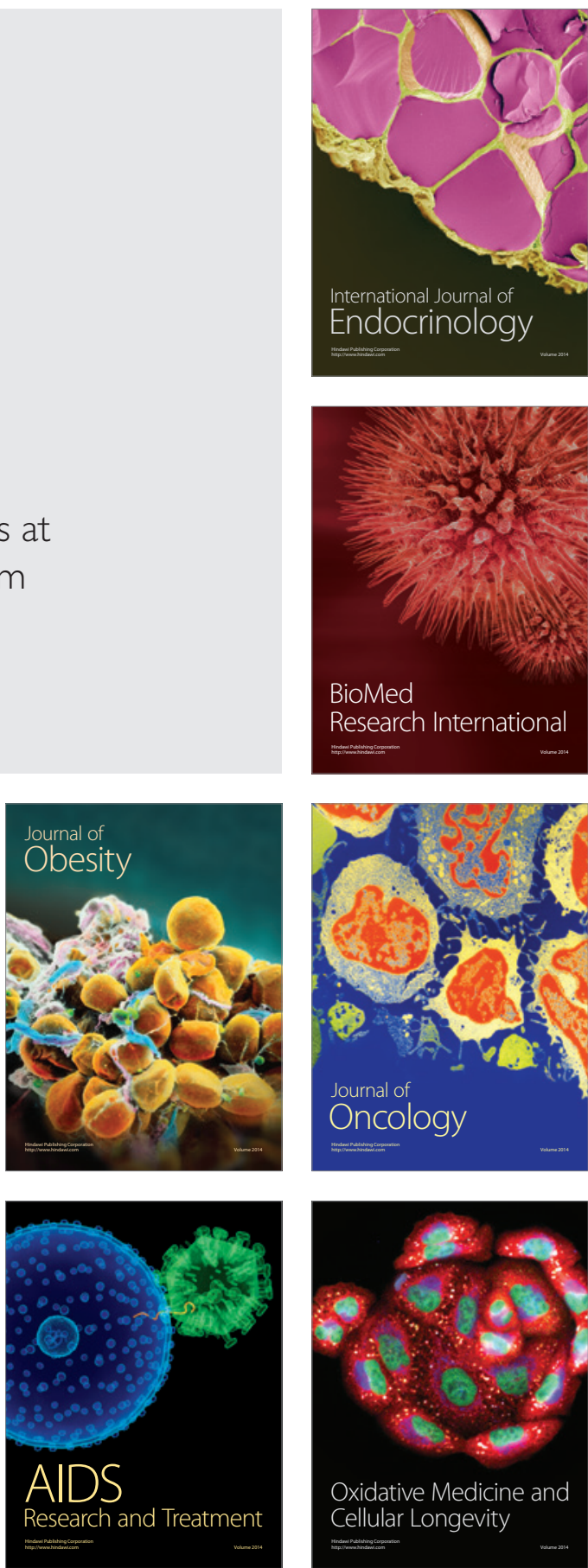